\title{
Functional outcomes with handsewn versus stapled anastomoses in the treatment of ultralow rectal cancer
}

\author{
Lisa Ramage ${ }^{1} \cdot$ Paul Mclean $^{1} \cdot$ Constantinos Simillis ${ }^{1} \cdot$ Shengyang Qiu ${ }^{1} \cdot$ Christos Kontovounisios $^{1,2} \cdot$ Emile Tan $^{1,3}$. \\ Paris Tekkis ${ }^{1,2}$
}

Received: 18 July 2017 / Accepted: 2 December 2017 / Published online: 8 January 2018

(c) The Author(s) 2018. This article is an open access publication

\begin{abstract}
Adequate oncological outcomes have been demonstrated with rectal resection and handsewn coloanal anastomosis (CAA) in tumours in close proximity to the internal anal sphincter. Our aim was to assess functional differences between handsewn CAA and ultralow stapled anastomosis. Participants were identified from a single-surgeon series. Included participants underwent anorectal physiology testing of anal sphincter function, in addition to completion of several questionnaires: Wexner Incontinence Score (WIS); Birmingham Bowel, Bladder and Urinary Symptom Questionnaire (BBUSQ); Low Anterior Resection Syndrome (LARS) Score; SF36. Non-parametric data compared using the Mann-Whitney $U$ test. 20 participants were included; 11 stapled and 9 handsewn. Mean follow-up was $2.95 \pm 1.97$ years. The mean LARS score was $21.9 \pm 1.97$ years in the stapled group versus $29.4 \pm 9.57$ in the handsewn group $(p=0.133)$. The Wexner incontinence score was significantly higher in the handsewn group $(p=0.0076)$, with a mean score of $4.6 \pm 3.69$ versus $10.9 \pm 4.76$. The incontinence domain of the BBUSQ was also significantly worse in patients with a handsewn anastomosis $(p=0.001)$. With the exception of general health $(p=0.035)$ and social functioning $(p=0.035)$, which were worse in the handsewn groups, the other six domains of the SF-36 showed no statistical difference between groups. Anorectal physiology scores were not significantly different. Handsewn CAA anastomosis is known to be safe and oncologically feasible. Patient selection should be vigorous, with preoperative counseling regarding the likelihood of incontinence to manage patients' expectations and promote comparable quality of life in the long-term.
\end{abstract}

Keywords Function · Coloanal anastomosis · Intersphincteric resection · Quality of life

\section{Introduction}

Consensus as to the adequate distal clearance margin required to safely achieve oncological tumour clearance in bowel cancer resection has shifted from $5 \mathrm{~cm}$ [1] to $1 \mathrm{~cm} \mathrm{[2].}$ This has facilitated the performance of ultralow and intersphincteric resection (ISR) in cases where the tumour is in proximity to or involving the uppermost edge of the internal

Christos Kontovounisios

c.kontovounisios@imperial.ac.uk

1 Department of Surgery and Cancer, Chelsea and Westminster Hospital, Imperial College London NHS Trust, 369 Fulham Road, London SW10 9NH, UK

2 Department of Colorectal Surgery, The Royal Marsden NHS Foundation Trust, London, UK

3 Department of Colorectal Surgery, Singapore General Hospital, Singapore, Republic of Singapore anal sphincter in patients who would have otherwise been left with a permanent colostomy. We have previously shown that comparable oncological outcomes can be achieved with handsewn coloanal anastomosis (CAA) [3]. With increasing emphasis being placed on long-term cancer survivorship, and the recognition that 5-year survival rates for rectal cancer patients are increasing, currently in the region of $60 \%$, the importance of acceptable functional outcomes and quality of life is a key issue in treatment decisions.

The aim of this paper was to ascertain whether there were any differences in long-term functional outcomes following rectal resection with CAA compared to an ultralow stapled anastomosis through analysis of a single-surgeon-patient cohort. 


\section{Methods}

This observational study received a favourable opinion from the Northampton Research Ethics Committee (REC14/LO/1653). Patients were identified from a prospectively maintained database of all rectal cancer resections performed across multiple sites by a single consultant colorectal surgeon with extensive experience in resection of complex and recurrent rectal tumours. Patients may have had additional neoadjuvant chemoradiotherapy or adjuvant chemotherapy.

Patients were contacted and invited to attend for comprehensive functional assessment carried out within a tertiary referral centre for Pelvic Floor Dysfunction.

Inclusion criteria were as follows:

1. Disease-free and oncological treatment completed at least 6 months ago.

2. Any diverting stoma reversed at least 6 months ago.

3. Either performance of a handsewn (coloanal) anastomosis OR a stapled anastomosis with anastomotic height within $3 \mathrm{~cm}$ of the dentate line.

Exclusion criteria:

1. Active proctitis.

2. Permanent diverting stoma.

3. Recurrent or distant disease.

Participants who consented to study inclusion were invited to attend a one-off assessment which included patient interview, the completion of several validated patient questionnaires which aimed to assess functional outcomes, quality of life (QoL) data and postoperative sexual function:

1. Wexner Incontinence Score [4].

2. Birmingham Bowel, Bladder and Urinary Symptom Questionnaire, (BBUSQ) [5]: four domains: constipation, evacuation, faecal incontinence, urinary.

3. Low Anterior Resection Syndrome (LARS) Score [6].

4. Short-Form 36 (SF-) 36 [7].

5. Additionally, patients were asked to complete a sexual function score (Male Sexual Health Questionnaire, MSHQ [8], and Female Sexual Function Index, FSFI) [9], although completion of these was entirely voluntary.

Following from this, patients underwent physical examination, which included digital rectal examination (DRE) and anorectal physiology (ARP) assessment of motor and sensory function.

\section{Surgical methods}

In all cases, a laparoscopic approach was performed where feasible. Surgical methods employed by the operating surgeon to create a handsewn anastomosis have previously been described [3]. Patients who underwent handsewn anastomosis had one of three slightly different approaches depending on the relation of the tumour to the dentate line, as per the classification outlined by Rullier et al. [10]. A straight coloanal anastomosis was performed in all cases.

\section{Anorectal physiology}

Anorectal physiology was performed using T-DOC ${ }^{\circledR}$ AirCharged ${ }^{\mathrm{TM}}$ ARM Catheters. These have four pressure sensors measuring four quadrants of the anal sphincter, plus a distal balloon which is slowly filled to obtain sensory responses.

The pressure sensors were connected to the Delphis IP processor by Laborie Urodynamics, The procedure was carried out in the left lateral position. After DRE was performed to assess for any stricture or contraindications to insertion, the catheter was inserted into the anal canal.

\section{Motor function assessment}

The maximum resting pressure (in $\mathrm{mmHg}$ ) was noted at the high-pressure zone (HPZ). The mean incremental squeeze pressure was calculated as an average of three squeeze readings taken at the level of the HPZ. The mean five-second incremental squeeze pressure calculated in a similar manner. Lastly, the mean cough squeeze increment was calculated.

\section{Sensory function assessment}

A balloon at the end of the catheter was slowly inflated with air whilst inside the rectum. Patients were asked to indicate the volume at which they were first aware of the balloon (threshold volume), then the volume at which they would usually consider opening their bowels (urge volume), before finally the maximal volume which they could tolerate (threshold volume).

\section{Statistical analysis}

Non-parametric data were compared using Mann-Whitney $U$ test. Data analysis was performed using SPSS software. 
A $p$ value of $<0.05$ was considered to be statistically significant.

\section{Results}

\section{Study demographics}

A total of 20 patients were recruited to this study over a 12 month period. There were 9 CAA versus 11 stapled anastomoses. The demographics of each group are shown in Table 1.

Follow-up from date of surgery to date of assessment was at a mean of 2.95 years \pm 1.97 years overall. One patient in the stapled versus three in the handsewn group required the use of rectal irrigation after restoration of normal bowel continuity. Three patients in the handsewn group required sacral nerve stimulation.

\section{Functional scores}

The results of the LARS Score, Wexner Incontinence Score and Birmingham Bowel, Bladder and Urinary Symptom Questionnaire are shown in Table 2.

The mean LARS Score was $21.9 \pm 10.86$ in the stapled versus $29.4 \pm 9.57$ in the handsewn group, and was not statistically different between groups ( $p=0.133$ ).
Table 2 Functional scores

\begin{tabular}{lccl}
\hline & Handsewn & Stapled & $p$ value \\
\hline LARS Score & $29.4 \pm 9.57$ & $21.9 \pm 10.86$ & 0.133 \\
Wexner Incontinence & $10.9 \pm 4.76$ & $4.6+/ 03.69$ & 0.0076 \\
$\quad$ Score & \multicolumn{4}{c}{} \\
Birmingham Bowel, Bladder and Urinary Symptom Questionnaire \\
Constipation domain & $35.37 \pm 19.03$ & $41.0 \pm 9.82$ & 0.182 \\
Evacuation domain & $23.58 \pm 10.65$ & $16.19 \pm 11.02$ & 0.182 \\
Faecal incontinence & $53.70 \pm 27.038$ & $16.67 \pm 11.79$ & 0.001 \\
Urinary domain & $12.96 \pm 10.04$ & $12.61 \pm 9.12$ & 0.968 \\
\hline
\end{tabular}

The Wexner incontinence score was significantly higher in the handsewn group $(p=0.0076)$, with a mean score of $4.6 \pm 3.69$ versus $10.9 \pm 4.76$.

The Birmingham Bowel, Bladder and Urinary Symptom Questionnaire (BBUSQ) is scored from 0 to $100 \%$ for each of the four domains (constipation, evacuation, faecal incontinence and urinary), with a higher score indicating worse symptoms. Neither group had an "abnormal" score in the constipation domain (abnormal $>64 \%$ ), with a mean of $35.37 \pm 19.03$ in the handsewn versus $41.0 \pm 9.82$ in the stapled group ( $p=0.133$ ). Similarly with the urinary domain, neither groups of patients had an abnormal score $(>20 \%)$, with a mean of $12.96 \pm 10.04$ in the handsewn versus $12.61 \pm 9.12$ in the stapled group $(p=0.968)$.

Table 1 Study demographics

\begin{tabular}{lll}
\hline & Handsewn $(n=9)$ & Stapled $(n=11)$ \\
\hline Age* & $66.5(55-72)$ & $57(33-77)$ \\
M:F ratio & $7: 2$ & $8: 3$ \\
Postoperative staging & T0N0: 1 & T2N0: 3 \\
& T1N0: 3 & T2N1: 1 \\
& T2N0: 4 & T3N0:3 \\
& T2N2: 1 & T3N1: 2 \\
Preoperative radiotherapy & & T3N2a: 1 \\
Neoadjuvant/adjuvant chemotherapy & 5 & 6 \\
Time surgery to assessment (years)* & 4 & 8 \\
Complications & $3.62(1.12-8.44)$ & $2.04(1.08-2.88)$ \\
& $3:$ anastomotic stricture & $2:$ anastomotic leak \\
Anastomosis height & $1:$ pelvic collection & $1:$ pelvic collection \\
& CAA 1: 2 & 3 cm $: 5$ \\
& CAA 2: 6 & 2 cm: 2 \\
Operation type & CAA 3: 1 & $1 \mathrm{~cm}: 3$ \\
& & $<1$ cm: 1 \\
\hline
\end{tabular}

CAA1-tumour $>2 \mathrm{~cm}$ from dentate line; anastomosis above dentate line with full preservation of internal anal sphincter. CAA2 - tumour 1-2 cm from dentate line, partial excision of internal anal sphincter; CAA3 - tumour involving/abutting uppermost internal anal sphincter, internal anal sphincter resection leaving $1 \mathrm{~cm}$ distal cuff

*Values are expressed as mean (range)

${ }^{\varphi} \mathrm{Cm}$ from dentate line 
The faecal incontinence score was significantly worse in the handsewn group $(53.7 \pm 27.03)$ versus $16.67 \pm 11.79$ in the stapled group ( $p=0.001)$; the stapled group had a score which was "normal" according to the validation criteria $(<17 \%)$.

The evacuation domain score was $23.58 \pm 10.65$ in the handsewn versus $16.19 \pm 11.02$ in the stapled group $(p=0.182)$. The score in the handsewn group was classified as "abnormal" according to the validation criteria cut-off $(>17 \%)$.

\section{Quality of life: SF-36 Score}

The results across the eight domains of the SF-36 are shown in Table 3. Scores for each domain are out of $100 \%$, with a lower score indicating worse QoL. The handsewn group had a worse score for each of the eight domains of the SF-36, however, this only reached statistical significance with general health $(58.81 \pm 22.19$ versus $76.50 \pm 14.90 \%$, $p=0.035)$ and social functioning (63.89 \pm 31.53 versus $91.25 \pm 15.64 \%, p=0.035)$.

\section{Anorectal physiology}

Anorectal physiology results are displayed in Table 4. With regards to motor function, no significant difference was detected between groups with either resting or squeeze pressures. Both groups had a mean value for the motor pressures which were within normal parameters.

With regards to sensory function, the handsewn group had a lower threshold volume than the stapled, although this was not statistically significant $(p=0.397)$. The urge volume and maximum tolerated volumes were also reduced in the handsewn group (36 versus $70 \mathrm{ml}$ and 63 versus $118 \mathrm{ml}$, respectively), both of which were approaching statistical significance.

\section{Sexual function}

Sexual function data was only available for two males in the stapled group, and three males and two females in the handsewn group. All males scored poorly on the erection scale. Table 5 gives the results. The results of the Female Sexual Function Index are shown in Table 6.

\section{Discussion}

Intersphincteric resection with handsewn coloanal anastomosis is an alternative to extralevator abdominoperineal excision (ELAPE) with comparable oncological outcomes in addition to the perceived benefits of maintenance of bowel continuity and prevention of a stoma. Current recommendations set out by the MERCURY II study group indicate that

Table 3 SF-36 Scores

\begin{tabular}{llll}
\hline SF-36 domain & Handsewn $(n=9)$ & Stapled $(n=10)$ & $p$ value \\
\hline Physical function & $76.91 \pm 27.2$ & $92.39 \pm 10.37$ & 0.211 \\
Role physical & $65.28 \pm 31.73$ & $85.00 \pm 21.08$ & 0.211 \\
Bodily pain & $70.83 \pm 27.95$ & $87.50 \pm 18.63$ & 0.182 \\
General health & $56.81 \pm 22.19$ & $76.50 \pm 14.90$ & 0.035 \\
Vitality & $50.69 \pm 19.38$ & $62.50 \pm 13.82$ & 0.278 \\
Social functioning & $63.89 \pm 31.53$ & $91.25 \pm 15.65$ & 0.035 \\
Role emotional & $73.96 \pm 28.33$ & $88.33 \pm 18.09$ & 0.274 \\
Mental health & $62.22 \pm 17.87$ & $74.00 \pm 7.38$ & 0.156 \\
\hline
\end{tabular}

Table 5 Male Sexual Health Questionnaire results

\begin{tabular}{lllll}
\hline Patient no. & Group & $\begin{array}{l}\text { Erec- } \\
\text { tion scale } \\
(\max =15)\end{array}$ & $\begin{array}{l}\text { Ejacula- } \\
\text { tion scale } \\
(\max =35)\end{array}$ & $\begin{array}{l}\text { Satisfac- } \\
\text { tion scale } \\
(\max =30)\end{array}$ \\
\hline 1 & Stapled & 3 & 1 & 20 \\
2 & Stapled & 4 & 32 & 16 \\
3 & Handsewn & 3 & 10 & 15 \\
4 & Handsewn & 0 & 21 & 18 \\
5 & Handsewn & 0 & 15 & 23 \\
\hline
\end{tabular}

Higher scores are indicative of better sexual function

Table 4 Anorectal physiology results

\begin{tabular}{lrrr}
\hline & Handsewn & \multicolumn{1}{c}{ Stapled } & $p$ value \\
\hline Motor & & & \\
Maximum resting pressure (mmHg) & $45.11 \pm 15.96$ & $55.0 \pm 12.10$ & 0.299 \\
Mean squeeze pressure increment (mmHg) & $68.56 \pm 60.78$ & $105.39 \pm 60.75$ & 0.299 \\
Mean five-second squeeze increment (mmHg) & $82.33 \pm 65.46$ & $69.69 \pm 39.76$ & 1.00 \\
Mean cough pressure increment (mmHg) & $87.67 \pm 62.46$ & $92.65 \pm 64.58$ & 1.00 \\
Sensory & & & \\
Threshold volume (ml) & $16.75 \pm 7.32$ & $30.7 \pm 28.20$ & 0.397 \\
Urge volume (ml) & $36.33 \pm 36.48$ & $70.43 \pm 65.24$ & 0.051 \\
Maximum tolerated volume (ml) & $63.33 \pm 72.43$ & $117.86 \pm 86.02$ & 0.051 \\
\hline
\end{tabular}


Table 6 Female Sexual Function Index results

\begin{tabular}{llllllll}
\hline Patient no. & Group & $\begin{array}{l}\text { Desire } \\
(\max =6)\end{array}$ & $\begin{array}{l}\text { Arousal } \\
(\max =6)\end{array}$ & $\begin{array}{l}\text { Lubrication } \\
(\max =6)\end{array}$ & $\begin{array}{l}\text { Orgasm } \\
(\max =6)\end{array}$ & $\begin{array}{l}\text { Satisfaction } \\
(\max =6)\end{array}$ & Pain $(\max =6)$ \\
\hline 1 & Handsewn & 6 & 1.2 & 1.2 & 1.2 & ND & 1.2 \\
2 & Handsewn & 3.6 & 4.8 & 5.4 & 5.2 & 2.4 & 5.6 \\
\hline
\end{tabular}

Higher scores are indicative of better sexual function where there is evidence of tumour extension on MRI beyond the muscularis propria or internal anal sphincter (IAS) and into the intersphincteric plane, then ELAPE should be performed [11]. Otherwise, ISR is considered to be a safe and valid alternative.

The technique of intersphincteric resection was first described by Lytle and Parks (1977), initially employed in resection of inflammatory bowel disease [12]. ISR in the context of rectal cancer was described by Braun et al. in 1992 [13], who reported a 62\% 5-year survival rate versus $58 \%$ in ISR and abdominoperineal excision patients, respectively. $85 \%$ of patients had also reported good postoperative functional results. Rullier et al. [2] published a series of 92 patients in 2005 who underwent ISR, including 72 patients with T3 and 6 patients with T4 tumours, where there was evidence of invasion of the internal anal sphincter. Median distance of the tumour was $3 \mathrm{~cm}$ from the anal verge (range $1.5-4.5 \mathrm{~cm}$ ). R0 resection was achieved in $89 \%$ of cases. They demonstrated a local recurrence rate of $2 \%$, and distal recurrence of $19 \%$. At 5 years, disease-free survival (DFS) was $70 \%$ and overall survival was $81 \%$. They concluded that the use of adjuvant radiotherapy reduced positivity of circumferential margins and facilitated successful resection in more advanced tumours, and that ISR was acceptable in such situations.

Usually, ISR with handsewn coloanal anastomosis is reserved for cases either where there has been a failure of the stapling device, or the tumour is close to or involving the sphincter complex, where the procedure acts as an alternative to APER. In this situation, a cuff of proximal internal anal sphincter may be removed with the specimen to achieve the minimum $1 \mathrm{~cm}$ distal cut-off margin required for oncological curative resection to be achieved.

We have previously described three CAA techniques based on the level of the tumour [3] and related to the classification described by Rullier et al. [10]: type 1 CAA was performed above the dentate line, therefore not involving the internal anal sphincter, type 2 CAA was performed for tumours $1-2 \mathrm{~cm}$ from the denate line, and involved partial excision of the internal anal sphincter; type 3 CAA was performed for intra-anal tumours which were either abutting the IAS or involving the uppermost portion, and also involved partial IAS excision to leave a minimum of $1 \mathrm{~cm}$ of distal IAS. In a group of 71 patients, R0 resection was achieved in $97.1 \%$, with the level of anastomosis having no relation to oncological outcomes. All patients had received an end-toend straight anastomosis with no pouch formation.

The above results demonstrate a significant difference in both the Wexner Incontinence Score and the incontinence domain of the BBUSQ, with those having handsewn anastomosis having a worse functional outcome. Despite this, there was no significant difference found in six out of eight of the SF-36 domains. The handsewn group had a significantly worse score in the general health and social function domains compared to the stapled group, which may be at least partially explained by the higher risk of faecal incontinence episodes, which could impact, on confidence in social situations and may be a recurrent source of embarrassment for sufferers. The handsewn group did, however, have a lower mean score for each of the other six domains of the SF-36 when compared to the stapled group, and whilst this did not prove to be statistically significant, a larger sample size may have eluded to a more significant difference.

There are several studies which consider postoperative function with ISR. Bittorf et al. [14] discuss a cohort of 33 patients who underwent ISR and coloanal anastomosis at the level of the dentate line $(2.9 \pm 1.1 \mathrm{~cm}) .12 / 33$ were given a colonic $\mathrm{J}$ pouch, the rest a straight coloanal anastomosis. 31/33 patients had closure of the diverting ileostomy. Of these, at least weekly incontinence of solid stool was experienced by $8 / 31$ patients, and $17 / 31$ for liquid stool and gas. 7/31 reported regular soilage. $24 / 31$ patients reported pad usage at least weekly. 9 patients reported no change in deferral time, whereas 14 had impaired deferral and 8 were completely unable to defer defecation. Interestingly, 7/9 of those with no impairment of deferral time had been given a colonic $\mathbf{J}$ pouch. The postoperative Wexner Score was $12 \pm 4.5$, with the patients with a straight anastomosis reporting a significantly worse incontinence score (13.4 vs 9.9, $p<0.05$ ). Chemoradiotherapy gave a significantly poorer Wexner Score $(p=0.054)$. Manometry results showed a reduction in the maximum and mean resting pressures when compared to healthy volunteers, with preserved squeeze pressure. Significantly worse tolerated volumes on sensory testing were seen with straight versus J pouch configurations, this was also the case with those who had undergone chemoradiotherapy.

Quality of life differences between low anterior resection (LAR), APER and intersphincteric resection (ISR) were considered by Konanz et al. [15] in a cohort comprised 
of 41 patients who underwent LAR, 33 had ISR and 50 APER. They found no significant differences between all three groups in terms of global quality of life, emotional, social and cognitive functioning. However, those undergoing LAR had higher physical functioning scores compared to APR patients $(p=0.0262)$, and APR patients had lower scores than ISR patients $(p=0.0280)$. ISR patients had significantly higher symptom scores with regards to defecatory disorders compared to those who had undergone LAR $(p<0.05)$; in addition, Wexner Incontinence Scores were higher in the ISR group (12.9 versus 9.5, $p<0.0005$ ).

In a series recently published by Koyama et al. [16] comparing outcomes with 77 ISR patients, 68 LAR patient and 33 APER patients. Local recurrence rates were similar between all three groups. With regards to function, they found no difference in frequency of defecation between ISR and LARS patients. Urgency was experienced in $57 \%$ of ISR patients and $47 \%$ of LAR patients. Failure of discrimination was present in $11 \%$ of ISR versus $3 \%$ of LAR patients. These differences did not reach statistical significance. However, pad usage was significantly more common in ISR patients (84 versus 33\%). The Wexner Incontinence Score was also significantly worse in ISR patients (8.1 versus 4.9 $p=0.004)$. Quality of life data was similar between groups.

Tokoro et al. [17] analysed results of 30 patients who underwent either partial, subtotal or total ISR (i.e. complete removal of internal anal sphincter) without adjuvant chemoradiation. In patients who had undergone partial ISR, postoperative Wexner Score significantly improved from 3 to 6 months postoperatively. By 6-12 months, there was a trend in those who had had a subtotal or total ISR towards improved function. At 3, 6 and 12 months, there was no significant differences between groups, however, those who did not suffer with concomitant stricture did have significant improvement of Wexner Scores from baseline compared from those who strictured. The presence of a stricture was also linked to ongoing nocturnal defecation and urgency, and worse outcomes at 12 months with regards to bowel frequency, fragmentation and urgency. Overall, the volume of residual internal anal sphincter was not found to affect bowel function.

Despite the increased risk of faecal incontinence with handsewn CAA, we have shown no significant differences in QoL in most domains. Overall, handsewn anastomosis has been shown to be safe and oncologically feasible compared to other techniques; however, it should be performed in specialist centres with experience of performing sphincter-preserving surgery. It is vital that patients are carefully selected for resection with CAA, taking into consideration factors such as patient age, any pre-existing functional deficit, the patient's socioeconomic background and the potential need for any further adjuvant treatment. We would advocate full assessment of sphincter function preoperatively to include anorectal physiology and in women with a history of previous vaginal delivery, endoanal sphincter ultrasound to check sphincter integrity.

\section{Compliance with ethical standards}

Conflict of interest The authors declare that they have no conflict of interest.

Research involving human participants and/or animals All procedures performed in studies involving human participants were in accordance with the ethical standards of the institutional and/or national research committee and with the 1964 Helsinki declaration and its later amendments or comparable ethical standards. The study was formally approved by the Ethics Committee of the institution where it was developed.

Informed consent Informed consent was obtained from all individual participants included in this study.

Open Access This article is distributed under the terms of the Creative Commons Attribution 4.0 International License (http://creativecomm ons.org/licenses/by/4.0/), which permits unrestricted use, distribution, and reproduction in any medium, provided you give appropriate credit to the original author(s) and the source, provide a link to the Creative Commons license, and indicate if changes were made.

\section{References}

1. Williams NS, Dixon MF, Johnston D (1983) Reappraisal of the 5 centimetre rule of distal excision for carcinoma of the rectum: a study of distal intramural spread and of patients' survival. Br J Surg 70:150-154

2. Rullier E, Laurent C, Bretagnol F, Rullier A, Vendrely V, Zerbib $F$ (2005) Sphincter-saving resection for all rectal carcinomas: the end of the 2-cm distal rule. Ann Surg 241:465-469

3. Tekkis P, Tan E, Kontovounisios C, Kinross J, Georgiou C, Nicholls RJ et al (2015) Hand-sewn coloanal anastomosis for low rectal cancer: technique and long-term outcome. Colorectal Dis 17:1062-1070. https://doi.org/10.1111/codi.13028

4. Jorge JM, Wexner SD (1993) Etiology and management of fecal incontinence. Dis Colon Rectum 36:77-97

5. Hiller L, Radley S, Mann CH, Radley SC, Begum G, Pretlove SJ et al (2002) Development and validation of a questionnaire for the assessment of bowel and lower urinary tract symptoms in women. BJOG Int J Obstet And Gynaecol 109:413-423

6. Juul T, Battersby NJ, Christensen P, Janjua AZ, Branagan G, Laurberg S et al (2015) Validation of the English Translation of the Low Anterior Resection Syndrome Score (The LARS score). Colorectal Dis. https://doi.org/10.1111/codi.12952

7. Brazier JE, Harper R, Jones NM, O'Cathain A, Thomas KJ, Usherwood T et al (1992) Validating the SF-36 health survey questionnaire: new outcome measure for primary care. BMJ (Clin Res Ed) 305:160-164

8. Rosen RC, Catania J, Pollack L, Althof S, O'Leary M, Seftel AD (2004) Male Sexual Health Questionnaire (MSHQ): scale development and psychometric validation. Urology 64:777-782. http s://doi.org/10.1016/j.urology.2004.04.056

9. Isidori AM, Pozza C, Esposito K, Giugliano D, Morano S, Vignozzi L et al (2010) Development and validation of a 6-item version of the female sexual function index (FSFI) as a diagnostic 
tool for female sexual dysfunction. J Sex Med 7:1139-1146. http s://doi.org/10.1111/j.1743-6109.2009.01635.x

10. Rullier E, Denost Q, Vendrely V, Rullier A, Laurent C (2013) Low rectal cancer: classification and standardization of surgery. Dis Colon Rectum 56:560-567. https://doi.org/10.1097/DCR.0b01 $3 \mathrm{e} 31827 \mathrm{c} 4 \mathrm{a} 8 \mathrm{c}$

11. Battersby NJ, How P, Moran B, Stelzner S, West NP, Branagan G et al (2015) Prospective validation of a low rectal cancer magnetic resonance imaging staging system and development of a local recurrence risk stratification model: the MERCURY II Study. Ann Surg. https://doi.org/10.1097/sla.0000000000001193

12. Lyttle JA, Parks AG (1977) Intersphincteric excision of the rectum. Br J Surg 64:413-416

13. Braun J, Treutner KH, Winkeltau G, Heidenreich U, Lerch MM, Schumpelick V (1992) Results of intersphincteric resection of the rectum with direct coloanal anastomosis for rectal carcinoma. Am J Surg 163:407-412

14. Bittorf B, Stadelmaier U, Gohl J, Hohenberger W, Matzel KE (2004) Functional outcome after intersphincteric resection of the rectum with coloanal anastomosis in low rectal cancer. Eur J Surg Oncol J Eur Soc Surg Oncol Br Assoc Surg Oncol 30:260-265. https://doi.org/10.1016/j.ejso.2003.11.011

15. Konanz J, Herrle F, Weiss C, Post S, Kienle P (2013) Quality of life of patients after low anterior, intersphincteric, and abdominoperineal resection for rectal cancer-a matched-pair analysis. Int J Colorectal Dis 28:679-688. https://doi.org/10.1007/s00384-013$1683-\mathrm{z}$

16. Koyama M, Murata A, Sakamoto Y, Morohashi H, Takahashi S, Yoshida E et al (2014) Long-term clinical and functional results of intersphincteric resection for lower rectal cancer. Ann Surg Oncol 21(Suppl 3):S422-S428. https://doi.org/10.1245/s104 34-014-3573-1

17. Tokoro T, Okuno K, Hida J, Ueda K, Yoshifuji T, Daito K et al (2013) Analysis of the clinical factors associated with anal function after intersphincteric resection for very low rectal cancer. World J Surg Oncol 11:24. https://doi.org/10.1186/1477-7819 $-11-24$ 